\title{
Environmental sustainability of small hydropower schemes in Tibet: An emergy-based
}

\section{comparative analysis}

\author{
Lixiao Zhang ${ }^{\mathrm{a}}$, Mingyue Pang ${ }^{\mathrm{a},{ }^{*}}$, Changbo Wang ${ }^{\mathrm{a}}$, Sergio Ulgiati ${ }^{\mathrm{a}}$, \\ ${ }^{a}$ State Key Joint Laboratory of Environmental Simulation and Pollution Control, School of Environment, \\ Beijing Normal University, Beijing 100875, China \\ ${ }^{b}$ Department of Environmental Sciences, Parthenope University of Naples, Centro Direzionale-Isola C4, \\ 80143 Naples, Italy \\ * Corresponding author. Tel.: +86 10 58807266; Fax: +86 1058807266. \\ E-Mail address: zhanglixiao@bnu.edu.cn (Lixiao Zhang), pangmingyue@mail.bnu.edu.cn (Mingyue Pang), \\ changbo@mail.bnu.edu.cn (Changbo Wang), sergio.ulgiati@uniparthenope.it (Sergio Ulgiati)
}


Abstract: Exploring safe and sustainable hydropower, with regard to the size and scheme, is of particular importance to avoid unsettling the fragile ecology in Tibet. Through emergy analysis, this study aimed to assess and compare the environmental performance and sustainability of three different small hydropower (SHP) schemes that are currently in use, i.e., dam-toe, diversion and hybrid, in the Nagqu Prefecture of Tibet. The results indicate that the main difference among the three schemes is the high emergy cost associated with the sizeable dam and related sediment deposition. Correspondingly, the diversion scheme without the dam component is superior to the other two schemes with respect to environmental performance. Considering the necessity of SHP in sparsely populated Tibet, the diversion scheme is recommended more highly than the other two schemes for new SHP plants that are being planned for construction. Because of the much higher resource cost but smaller installed capacity, all three case plants in Tibet present worse performance than their counterparts in Guizhou Province. These results help to encourage China's policy makers to be conservative and proceed with caution regarding SHP development in the fragile Tibetan ecosystem, although SHP has played and will continue to play an essential role in rural electrification in this unique region.

Keywords: small hydropower; emergy analysis; environmental sustainability; Tibet 


\section{Introduction}

The Himalayan region, which contains a very large amount of glaciers, second only to the Arctic and Antarctic, is called the "third pole" and the "water tower of Asia" (Qiu, 2008). It gives birth to many major Asian rivers, including the Yangtze, Brahmaputra, and Lancang-Mekong Rivers, as well as countless small streams. The quantity of water flowing from the plateau and the steep gradients mean that the hydropower potential of these rivers is among the highest in the world. Many Himalayan countries have set ambitious goals to harness this "water tower" into a "power tower" in the form of small and large hydropower projects (Kumar and Katoch, 2014). The Chinese government has also proposed Tibet, the main part of the eastern Himalayan region, to be the main hydropower development base in China after 2020 to sustain its rapid economic growth and optimize its energy structure (TARG, 2011; Wu et al., 2016).

Tibet is an environmentally strategic area, and its importance to the sustainability of the world's fragile ecosystem cannot be overstated. With an average altitude over 4000 meters, the ecosystem in Tibet is very fragile and difficult to restore if severely damaged (Zhang, 2000). Since the 1980s, large areas have been enclosed as nature reserves to protect this valuable ecosystem (Zhong et al., 2006). In this context, it is of the utmost importance to explore hydropower resources that are safe and sustainable for the Tibet plateau region.

Currently, although the development of large hydropower (LHP) projects in Tibet has been actively promoted, there are still difficult problems, such as those of ecology, society and politics (Han et al., 2014; XHN, 2014). By contrast, small hydropower (SHP) ${ }^{1}$ is always characterized as more environmentally friendly due to its small size (Paish, 2002). Actually, before the

\footnotetext{
${ }^{1}$ The definition of SHP differs from country to country and changes with national economy and rural energy consumption. Currently, in China, SHP refers to hydropower plants with an installed capacity of up to 50 MW (CWSY, 2012).
} 
construction of LHP projects, SHP had been vigorously promoted for electrification in Tibet in the past several decades (Chong, 2009). However, there is no scientific evidence in the available literature regard the "environmental friendliness" of SHP in Tibet. To the best of our knowledge, there is no specific research evaluating the environmental sustainability of SHP in China's Tibet plateau region. Although the previous emergy analysis studies confirmed the superior environmental performance of a grid-connected SHP over LHP in Guizhou Province (Zhang et al., 2014), the SHP in Tibet is different from that in other provinces of China. Most SHP plants in Tibet are off-grid operations, producing less electricity with the same installed capacity due to unstable power loads and poor management, whereas their disturbances to the landscape remain unknown compared with those in other provinces. In addition, another notable problem associated with SHP development in Tibet is scheme selection. The main SHP schemes include dam-toe, diversion and hybrid, according to the methods of concentrating the water head (Yao et al., 2010). For different SHP development schemes, disturbances to the local ecosystem are different because different components are involved in engineering, see Fig. 1. With little consideration of their impact on the local ecosystem, SHP schemes in Tibet usually depended on the available financial support for construction, which mainly comes from the central government. In addition, the lack of necessary knowledge related to the ecological impacts of different SHP schemes in Tibet is also responsible for the disregard of the development scheme. In fact, relevant studies are lacking not only in Tibet but also across the whole Himalayan region, which is one of the current "hotspots" for the development of SHP (Kumar and Katoch, 2014). Therefore, the environmental impacts and sustainability of different SHP schemes must be evaluated in a systematic way to aid in the rational selection of more ecologically sustainable SHP schemes in Tibet and the whole Himalayan region. 
Fig. 1 could be here.

Sustainability, which mainly means to "maintain" or "support", can be explained as "the capacity to endure" (Yang et al., 2013). Thus, to assess the sustainability of a system, qualitative and quantitative evaluations of the support that the system requires and receives from the surrounding environment, including nature and human society, are needed (Zhang et al., 2007a). Emergy analysis, rooted in thermodynamics, can provide a biophysical evaluation of the cumulative environmental and economic support to a system, as well as consider the quality difference among resource inputs (Odum, 1996; Wu et al., 2015). Defined as the available energy of one type that was previously directly and indirectly required for a product or service, emergy is commonly quantified in solar energy equivalents and expressed as solar emJoules (seJ) (Odum, 1996; Lan et al., 2002; Zhang et al., 2013). By converting different forms of energy, materials and human services into a common energetic basis, a set of emergy indices can be calculated to measure the environmental performance of a system, e.g., the resource use efficiency, environmental loading and overall sustainability (Brown and Ulgiati, 1997).

Within a unified evaluation framework that was developed and further illustrated by Odum and his colleagues (Odum, 1996; Brown and Ulgiati, 1997; Bakshi, 2002; Ulgiati and Brown, 2009), emergy analysis has been successfully applied to assess different systems, such as agricultural, urban, and industrial systems, as well as renewable energy technologies, at the regional, national or global scales (Ulgiati et al., 1994; Odum, 1996; Chen et al., 2006; Zhang et al., 2007a; Jiang et al., 2008; Chen and Chen, 2009; Zhang et al., 2009a; Ciotola et al., 2011; Liu et al., 2011; Zhang et al., 2012a; Zhang et al., 2012b; Yang et al., 2013; Wu et al., 2014). A few studies have also been conducted to evaluate hydropower plants using emergy analysis. Brown and McClanahan (1996) evaluated the benefits and costs of two proposed dams on the Mekong 
River in Thailand via the emergy method and further discussed the impacts of sediments on the benefits of the dams. Later, Kang and Park (2002) and Yang et al. (2012) applied a similar framework to evaluate a proposed multipurpose dam in Korea and the Three Gorges Dam in China, respectively. As mentioned above, we have applied the emergy method to evaluate and confirm the superior environmental performance of a SHP plant in Guizhou Province (Zhang et al., 2014). When downstream drying-up occurred due to the SHP operation, its ecological impacts tended to be severe if ecosystem service losses were considered as additional emergy costs of the SHP operation (Pang et al., 2015).

Following our previous research, this study presents an emergy analysis of three SHP plants, i.e., a dam-toe scheme, diversion scheme and hybrid scheme, in the Nagqu Prefecture of Tibet to shed light on the environmental performance and sustainability of different SHP schemes in Tibet. The main objectives of this paper are (1) to evaluate and compare the environmental performance of different SHP schemes in Tibet with respect to resource use, system productivity, environmental impacts and sustainability; (2) to provide the overall profile of environmental sustainability of SHP plants in Tibet by comparing them with those in other provinces; and (3) to explore the implications for ecologically sustainable development of SHPs in Tibet related to scheme choice and development strategy.

\section{Materials and methods}

\subsection{Location and study sites}

Nagqu Prefecture is located in the north of the Tibet Autonomous Region, the hinterland of the Tibetan Plateau. To date, only Nagqu County, the administrative center of Nagqu Prefecture, has access to the state power grid, while other counties still mainly rely on SHPs for electricity 
supply. Thus, for the three SHP schemes, three corresponding case plants with similar installed capacities serving three county towns were selected, i.e., the Jiqian, Aerdan, and Lhari SHP plants located in Biru, Baqen and Lhari County, respectively (see Fig. 2); all three plants are designed solely for electricity production without other purposes.

Fig. 2 could be here

As shown in Fig. 1, the main difference among the three SHP schemes exists in the component of civil works. The Jiqian SHP plant is a dam-toe scheme that is located on the main stream of the Nujiang River in Biru County. Specifically, it is a power station seated in the main river channel. The concrete-type dam forms a 1.53 million $\mathrm{m}^{3}$ volume reservoir. For the diversion scheme, the Aerdan SHP plant, which only has a weir but no dam, was selected. It is constructed close to the Yiqu River, a second-order tributary of the Nujiang River in Baqen County. Through the intake at the weir, the water is diverted into an 833-meter-long man-made channel and flows into the forebay. The water descends to the hydro-turbines through the penstock and then returns to the main channel through the tailrace. Combining the features of dam-toe and diversion schemes, the Lhari SHP plant is a hybrid scheme and is located on the Xiongqu River, a second-order tributary of the Brahmaputra River in Lhari County. This earth-rock dam forms a reservoir with a volume of 2.6 million $\mathrm{m}^{3}$. Through the intake, the water flows into a man-made 110-meter-long water tunnel. Together, the dam and tunnel form the water head. The main parameters of the three SHP plants are listed in Table 1.

Table 1 could be here

\subsection{Emergy analysis}


Odum and his colleagues provide detailed explanations of the application of emergy accounting procedures to a variety of systems (Odum, 1996; Lan et al., 2002; Ulgiati and Brown, 2009). First, the aggregated system diagrams of the three SHP schemes are represented in Fig. 3. Diagrams show their boundaries and the emergy sources driving the processes. For SHP schemes, different emergy sources can be aggregated into three types: free local renewable resources (R), mainly referring to the water flows from the upper reach (from the upstream watershed); free local nonrenewable resources $(\mathrm{N})$, such as the minerals used for the construction and sediment blocked in the reservoir; and purchased inputs $(\mathrm{F})$ from the main economy, such as labor and machinery. The $\mathrm{F}$ group can be further divided into renewable $\left(\mathrm{F}_{\mathrm{R}}\right)$ and nonrenewable $\left(\mathrm{F}_{\mathrm{N}}\right)$ fractions of purchased inputs according to their renewability factors, the values of which were based on previous work by Ulgiati et al. (1994, 2005), Ortega et al. (2005), Agostinho et al. (2008) and Zhang et al. $(2011,2013)$. The $F_{R}$ was calculated by multiplying the flows of the materials and services that enter the system by the renewability factor. Correspondingly, $\mathrm{F}_{\mathrm{N}}$ represents the nonrenewable fraction.

The second step is to establish detailed emergy analysis tables for each system under study. The data for the construction and operation of the SHP plants were obtained from the plants' design reports and interviews with the managers of the plants. Because 1 year was taken as the time scale for the present analysis of the three SHP systems, all input flows for plant construction (materials and equipment) are divided by the plant lifetime. The raw data were multiplied by the appropriate specific emergy factors (UEV=Unit Emergy Value, seJ/unit of flow), designated transformities when flows are measured as available energy units (seJ/J), to convert energy (joule), mass (kg) and money (\$) quantities into emergy units. The global emergy baseline applied in this study was 12.0E+24 seJ/yr (Brown et al., 2016). The UEVs employed in this 
study include the labor and services required to produce economic goods. To avoid double counting, services were not calculated separately. Finally, the resources and emergy-based indices can be calculated to evaluate the environmental performance of the production systems, such as the resource use, system productivity, environmental impacts and sustainability.

Fig. 3 could be here

\section{Results and discussion}

\subsection{Emergy accounting}

The detailed emergy flows of the three SHP production systems are presented in Table 2 . Fig. 4 shows the detailed emergy inputs of each production system, reflecting that the emergy structures (i.e., the types of supporting emergy sources) of the three development schemes look very similar.

Table 2 could be here

According to our classification, free local renewable resources refer to the water flows from the upper reach to drive the hydro-turbines. The differences in the emergy input $\mathrm{R}$ among the three systems is distinguished by the water head, discharge flow and annual operation time of the plant. Based on the data from the design reports, the emergy of the water flow inputs into the diversion-scheme system is $7.15 \mathrm{E}+17 \mathrm{seJ} / \mathrm{yr}$, slightly lower than the other two systems, $1.85 \mathrm{E}+18 \mathrm{seJ} / \mathrm{yr}$ for the dam-toe-scheme system and $9.63 \mathrm{E}+17 \mathrm{seJ} / \mathrm{yr}$ for the hybrid-scheme system.

For free local nonrenewable resources, the main concern is the construction minerals used for the civil works and the sediment blocked in the reservoir. The diversion-scheme plant has no reservoir; thus, the input of sediment was missing for this scheme; however, it is a significant 
cost for the other two schemes. The emergy of the sediment in the dam-toe-scheme plant and hybrid-scheme plant is $9.13 \mathrm{E}+17 \mathrm{seJ} / \mathrm{yr}$ and $1.11 \mathrm{E}+18 \mathrm{seJ} / \mathrm{yr}$, respectively. In terms of construction minerals, the dam-toe-scheme plant requires the highest emergy input $(5.05 \mathrm{E}+18$ seJ/yr) due to the complex civil works, especially the construction of the dam. The hybrid-scheme plant comes second $(2.30 \mathrm{E}+18 \mathrm{seJ} / \mathrm{yr})$. The diversion-scheme plant requires the least amount of construction minerals $(1.34 \mathrm{E}+18 \mathrm{seJ} / \mathrm{yr})$ because it does not involve a dam structure. Totally, the local nonrenewable resources are the largest inputs in their emergy structures.

With regard to the purchased resources, the dam-toe-scheme, diversion-scheme, and hybrid-scheme plants are 3.69E+18 seJ/yr, 1.03E+18 seJ/yr, and $1.78 \mathrm{E}+18 \mathrm{seJ} / \mathrm{yr}$, respectively. In each production system, a large quantity of cement is required in the civil works to make concrete, especially in the dam-toe-scheme plant, i.e., $1.25 \mathrm{E}+18 \mathrm{seJ} / \mathrm{yr}$. The item of construction services, including the reconnaissance and design of the plant, machinery rentals for civil works and equipment installation, is also a large cost in the emergy budget due to the difficult working environment in Tibet. Similarly, a high emergy value is associated with the services for the operation cost. Across the three systems, the above three items are the three largest emergy flows in the F category. In addition, the steel, wood, explosives, machinery, and diesel fuel used for civil works, as well as the labor and machine oil, are all necessary inputs to construct and operate these plants. Moreover, transport fuel is also a significant input in the emergy structures because nearly all of the purchased inputs must be imported from outside the Tibet region or from Lhasa. The long transport distance consumes a considerable amount of diesel fuel.

Overall, the annual total emergy use (U) of the dam-toe-scheme, diversion-scheme and hybrid-scheme systems is summed as $1.15 \mathrm{E}+19 \mathrm{seJ}, 3.08 \mathrm{E}+18$ seJ and $6.16 \mathrm{E}+18$ seJ of solar 
emergy to produce $4.66 \mathrm{E}+13 \mathrm{~J}, 1.97 \mathrm{E}+13 \mathrm{~J}$ and $2.58 \mathrm{E}+13 \mathrm{~J}$ of electricity, respectively.

Fig. 4 could be here

\subsection{Emergy-based indices for the three plants}

Based on the emergy accounting rules, a number of indices were calculated for the assessment of the environmental performance and sustainability of the SHP systems, namely, transformity, renewable percent (\%REN), emergy yield ratio (EYR), environmental loading ratio (ELR), and emergy sustainability index (ESI) (Odum, 1996; Ulgiati and Brown, 1998). As presented in Table 3, a diversion-scheme SHP plant in Guizhou Province was selected for comparison to obtain better insight into the SHP plants in Tibet (Zhang et al., 2014).

Transformity is a crucial parameter measuring the required environmental support to produce a product, indicating the overall efficiency of a production system from the point of view of the biosphere. When comparing different systems yielding the same output, a lower transformity can be interpreted as a measure of higher efficiency, or lower ecological production cost, as fewer resources are needed to produce the same amount of product (Odum, 1996; Zhang et al., 2011). Among the three investigated systems, the lowest transformity is found for the diversion-scheme plant $(1.56 \mathrm{E}+05 \mathrm{seJ} / \mathrm{J})$, suggesting that the diversion scheme has a relatively higher efficiency in converting water resources to electricity than the dam-toe-scheme and hybrid-scheme plants $(2.47 \mathrm{E}+05 \mathrm{seJ} / \mathrm{J}$ and $2.39 \mathrm{E}+05 \mathrm{seJ} / \mathrm{J}$, respectively). This is largely due to the simplicity of the civil works in the diversion-scheme plant, especially the absence of the need to build a dam. In contrast, the sizeable dams in the dam-toe-scheme and hybrid-scheme plants require a large amount of resource inputs from the environment and economy. Moreover, due to the absence of a sizeable reservoir, sediment would not be trapped by the diversion-scheme plant, 
which is also a significant emergy cost in the other two plants. However, all three plants are less efficient than the Hongyan plant in Guizhou Province, whose transformity is $7.81 \mathrm{E}+04 \mathrm{seJ} / \mathrm{J}$. Although the installed capacities of the three plants in Tibet are much smaller than that of the Hongyan plant $(8 \mathrm{MW})$, the consumption of both local construction minerals and economic resources is higher due to the unfavorable working conditions and long transportation distance required to deliver the building materials. This also demonstrates the common phenomenon that the SHP plants in Tibet have high associated costs but a low electricity output, which would significantly affect the overall environmental performance of SHPs in Tibet.

The renewable percent (\%REN) is the ratio of the renewable emergy input divided by the total emergy use $\left(\left(\mathrm{R}+\mathrm{F}_{\mathrm{R}}\right) / \mathrm{U}\right)$. The \%REN of the three SHP plants in Tibet varies from 0.17 to 0.25 , much lower than that of the Hongyan plant (0.52), indicating that the plants in Tibet have a larger dependency on nonrenewable emergy support. Focusing only on the three plants in Tibet, the diversion-scheme system is driven by the highest \%REN (0.25), while the hybrid and dam-toe-based have similar profiles for this indicator, 0.18 and 0.17 , respectively. In the long run, a system with a higher renewable proportion is considered to be more sustainable, as it is more likely to be successful in economic competition, especially when nonrenewable resources are limited (Zhang et al., 2011).

The emergy yield ratio (EYR) is the emergy of the output divided by the emergy inputs from the economy $(\mathrm{U} / \mathrm{F})$, measuring the ability of a process to exploit local resources by investing resources from the economic system (Raugei et al., 2005; Ulgiati and Brown, 2012). Generally, the higher the EYR, the higher the relative contribution of the free resources to the process (Zhang et al., 2012a). Although the EYR of the three plants in Tibet (between 3.01 and 3.45) does not differ much from that of the Hongyan plant in Guizhou (4.40), it is mainly 
contributed by the utilization of local nonrenewable construction minerals rather than renewable river flows. In addition, the diversion-scheme plant has the highest conversion efficiency (indicated by its transformity), but it has the worst return on investment. Thus, it can be seen that a system could be efficient in converting available resources, but this has nothing to do with its ability to exploit the resources that are available locally. This further illustrates the argument that more than one indicator can be useful in gaining insights into the sustainability assessment and trends of investigated systems (Zhang et al., 2011).

The environmental loading ratio (ELR) refers to the ratio of nonrenewable (both local and imported) to renewable resources $\left(\left(\mathrm{N}+\mathrm{F}_{\mathrm{N}}\right) /\left(\mathrm{R}+\mathrm{F}_{\mathrm{R}}\right)\right)$. It is a critical indicator in the emergy methodological system, which provides a measure of the pressure on the environment due to the introduction and operation of a new system. The higher the value, the higher the stress on the environment. The ELR is directly related to the fraction of renewable resources in the emergy structure (Chen et al., 2006; Zhang et al., 2011). The ELR of the dam-toe-scheme and hybrid-scheme plants are 4.78 and 4.71, respectively, much higher than that of the diversion-scheme plant (2.92), suggesting that the two plants induce more negative impacts on the environment. However, the ELRs of all three plants in Tibet are significantly higher than that of the Hongyan plant (0.92), which can be attributed to more intensive investment of nonrenewable resources, but fewer renewable hydropower resources exploited.

Combining EYR and ELR (EYR/ELR), the emergy sustainability index (ESI) gives a comprehensive assessment of the system sustainability. As a relative measure, if the ESI is lower than 1, the system is considered to be unsustainable in the long run, and if the ESI falls between 1 and 5, the system is considered as moderately sustainable; the system is considered to be long-term sustainable with ESI higher than 5 (Ulgiati and Brown, 1998; Brown and Ulgiati, 
2002). In the present study, the ESI of the dam-toe-scheme and hybrid-scheme plants are 0.65 and 0.73 , respectively, both are lower than 1 . Although the two systems provide a high emergy return (indicated by EYR), they also exert severe stress on the local environment (indicated by ELR). Overall, they would be unsustainable in the long run. For the diversion-scheme system, the ESI value is 1.03 , slightly higher than 1 , indicating that it obtains a weak sustainability by providing a larger emergy return per unit of environmental loading generated.

Table 3 could be here

\subsection{Selection of sustainable SHP scheme in Tibet}

Through the comparison of emergy-based indicators, it can be seen that all three investigated SHP plants (off-grid) in Tibet perform much worse than the Hongyan plant (grid-connected) in Guizhou Province. This can be mainly attributed to the fact that the SHP plants in Tibet require a greater amount of nonrenewable resources from the environment and economy for construction and maintenance, but they produce much less electricity. Through personal communications with local decision-makers, it was learned that many SHP plants in Tibet are faced with this dilemma. Due to the small electricity requirement, the installed capacity of the plants is usually much smaller than the exploitable hydropower resources. However, the plant still needs a large amount of resources from the environment and economy for civil works. In addition to the off-grid operation condition, another possible factor is the frozen-ground condition in Tibet, which requires a larger amount of resources to strengthen the foundation of SHP plants (Jin et al., 2008). Overall, the SHP systems in Tibet show weak sustainability.

By focusing on the three investigated schemes in this study, it can be seen that the diversion SHP system performs much better than the other two schemes. Note that the water head of the 
selected diversion-scheme plant is $10 \mathrm{~m}$, even lower than that of the hybrid scheme, scarcely reflecting the advantage of the diversion scheme. If the water head is higher, the environmental performance of the diversion-scheme plant could be improved. The absence of a sizeable dam in the diversion-scheme plant means that it requires much fewer nonrenewable resources from the free environment and economy to harness the hydroenergy and generate electricity. In addition, the diversion-scheme plant would not trap sediment brought from the upper reaches in the reservoir, which is a significant cost for the other two plants. Therefore, the diversion-scheme plant is more environmentally friendly and sustainable.

For the new SHP plants that are being planned for construction in Tibet, the diversion scheme is highly recommended because of its lower resource investment and lower impact on the local ecosystem, as supported by our research results. Even for the diversion-scheme, however, improvements are still needed in the design and construction stages to optimize its environmental performance. For instance, the high percentage of construction materials in the emergy structure of the investigated systems highlights the importance of simplifying the civil engineering of SHP projects. These projects can be optimized by taking intelligent advantage of the local topography, e.g., using natural valleys to divert water flows and decreasing the consumption of resources in the construction of the diversion channels (Yi et al., 2010). Moreover, adopting integrated equipment through technical innovation can also improve the environmental performance of the systems by reducing the materials required by equipment production (Zhang et al., 2007b). If possible, the localized production of facilities is favored to benefit the environment, considering the remote position of Tibet from the eastern manufacturing centers in China. 


\subsection{New management strategies for existing SHP plants in Tibet}

According to the planning of the Tibetan government, a unified power grid inside Tibet is planned through the connection of three grids by 2020, and then, all 74 county towns in Tibet can be reached by the grid (Lan, 2015). In this context, our evaluation results could shed light on possible new management strategies for the existing SHP plants.

The relatively highly populated areas, e.g., county towns, could have access to the power grid in the near future. Thus, the existing SHP plants around these areas will no longer be indispensable for local residents and will face self-transition in light of their overall performance. The plants with good performance, e.g., the Aerdan plant in Baqen County in our study, are recommended to be connected to the grid and continue to operate; however, for those with evident ecological problems and poor performance, e.g., the Jiqian plant in Biru County, which has a high sediment deposition rate, dismantling would be an inevitable choice. As illustrated by the values of the ELR and ESI (4.78 and 0.65, respectively), the Jiqian SHP system has imposed a severe impact on the local ecosystem and would not be sustainable in the long run.

For the less densely populated areas where the main grids cannot reach, e.g., villages with several hundred individuals, SHP will still be an essential social service for local residents. The existing SHP plants are encouraged to continue to serve because it would not be environmentally and economically effective to build a new one or find other alternatives (Chen, 1992). Nevertheless, the operation and management of these plants should be updated, e.g., introducing advanced regulating equipment that can improve the operating conditions of off-grid plants (Guo, 2014).

As an important renewable energy resource, SHP is likely to expand across the world to 
cater to the energy demand of rural areas, especially in the Himalayan region (Liu et al., 2013; Kumar and Katoch, 2014). In this case, for any region with an ambitious plan to explore hydropower, the rigorous investigation and systematic evaluation of different SHP schemes is necessary to understand the ecological impacts incurred by massive intervention to local ecosystems. This is particularly meaningful to the Himalayan region, including Tibet, which is very sensitive to global climate change even without stress from the interior (Qiu, 2008). Therefore, it is never an error to decrease local anthropogenic disturbances to this already fragile ecosystem, no matter which SHP development schemes are adopted. In other words, Tibet should proceed with more caution during the process of electrifying the whole region.

\section{Conclusions}

This paper presented an emergy-based analysis of three SHP schemes (i.e., dam-toe, diversion and hybrid) in Tibet, China, by taking three corresponding case plants in the Nagqu Prefecture as examples. By quantifying different forms of inputs on a common basis, comparisons across different SHP systems could be accomplished. Further comparative analysis was conducted between the three case plants and a diversion-scheme SHP plant in Guizhou Province.

The results showed that only the diversion-scheme plant is in a weak sustainable pattern, whereas the dam-toe and hybrid schemes, whose ESI are 0.65 and 0.73 , respectively, both much lower than 1, are unsustainable in the long run. The overall environmental performance of the three schemes can be ranked as follows: diversion scheme> hybrid scheme> dam-toe scheme system. Therefore, the diversion scheme is recommended more highly than the other two schemes for the new SHP plants under planning in Tibet. However, further comparison of 
emergy based indicators shows that even the diversion-scheme plant performs much worse than its counterparts in Guizhou Province due to the much higher resources cost but smaller electricity output. It is usually assumed and is further quantitatively confirmed in our paper that SHP development with any scheme in Tibet could give rise to higher intervention to the ecosystem than for other regions in China. Therefore, for any case, Tibet should be conservative and proceed with caution regarding the development of SHP schemes.

Finally, several limitations of the present study should be acknowledged. This study quantifies the environmental impacts of SHP development induced by resource consumption, whereas additional impacts (e.g., possible loss of river ecosystem services and biodiversity) are not included in the evaluation framework. These impacts might require long-term on-site and remote-sensing monitoring of local ecosystems, which deserves our efforts in the future.

\section{Acknowledgements}

This work was supported by the National Natural Science Foundation of China (Grant No. 41371521) and National Science Foundation for Innovative Research Group (Grant No. 51421065).

\section{References}

Agostinho, F., Diniz, G., Siche, R., Ortega, E., 2008. The use of emergy assessment and the Geographical Information System in the diagnosis of small family farms in Brazil. Ecol. Model. 210, 37-57.

Bakshi, B.R., 2002. A thermodynamic framework for ecologically conscious process systems engineering. Comput. Chem. Eng. 26, 269-282. 
Bastianoni, S., Marchettini, N., Panzieri, M., Tiezzi, E., 2001. Sustainability assessment of a farm in the Chianti area (Italy). J. Clean. Prod. 9, 365-373.

Brown, M.T., Bardi, E., 2001. Handbook of Emergy Evaluation: A Compendium of Data for Emergy Computation Issued in a Series of Folios. Folio 3, Emergy of Ecosystems. Center for Environmental Policy, Environmental Engineering Sciences, University of Florida, Gainesville, FL. Available at: http://www.cep.ees.ufl.edu/emergy/publications/folios.shtml.

Brown, M.T., Campbell, D.E., Vilbiss, C.D., Ulgiati, S., 2016. The geobiosphere emergy baseline: A synthesis. Ecol. Model. (In Press).

Brown, M.T., McClanahan, T.R., 1996. Emergy analysis perspectives of Thailand and Mekong River dam proposals. Ecol. Model. 91, 105-130.

Brown, M.T., Ulgiati, S., 1997. Emergy-based indices and ratios to evaluate sustainability: monitoring economies and technology toward environmentally sound innovation. Ecol. Eng. 9, 51-69.

Brown, M.T., Ulgiati, S., 2002. Emergy evaluations and environmental loading of electricity production systems. J. Clean. Prod. 10, 321-334.

Chen, B., Chen, G.Q., 2009. Emergy-based energy and material metabolism of the Yellow River basin. Commun. Nonlinear Sci. Numer. Simul. 14, 923-934.

Chen, D., Webber, M., Chen, J., Luo, Z.H., 2011. Emergy evaluation perspectives of an irrigation improvement project proposal in China. Ecol. Econ. 70, 2154-2162.

Chen, G.Q., Jiang, M.M., Chen, B., Yang, Z.F., Lin, C., 2006. Emergy analysis of Chinese agriculture. Agric. Ecosyst. Environ. 115, 161-173.

Chen, W.M., 1992. Further strengthening small hydropower construction in Tibet Autonomous Region. China Rural Water Hydropower (5), 37-39 (in Chinese). 
Chong, J., 2009. Strive to develop rural hydropower to improve the life quality of residents in the border minority areas. China Water Power Electrification (5), 12-13 (in Chinese).

Ciotola, R.J., Lansing, S., Martin, J.F., 2011. Emergy analysis of biogas production and electricity generation from small-scale agricultural digesters. Ecol. Eng. 37, 1681-1691.

CWSY, 2012. China Water Statistical Yearbook 2012. China Water Power Press, Beijing (in Chinese).

Guo, J.Y., 2014. Technical measures to improve the off-grid operation of small hydropower plants. Small Hydro Power (1), 17-18 (in Chinese).

Han, M.Y., Sui, X., Huang, Z.L., Wu, X.D., Xia, X.H., Hayat, T., et al., 2014. Bibliometric indicators for sustainable hydropower development. Ecol. Indic. 47, 231-238.

Ingwersen, W.W., 2010. Uncertainty characterization for emergy values. Ecol. Model. 221, 445-452.

Jiang, M.M., Zhou, J.B., Chen, B., Chen, G.Q., 2008. Emergy-based ecological account for the Chinese economy in 2004. Commun. Nonlinear Sci. Numer. Simul. 13, 2337-2356.

Jin, H.J., Wei, Z., Wang, S.L., Yu, Q.H., Lu, L.Z., Wu, Q.B., et al., 2008. Assessment of frozen-ground conditions for engineering geology along the Qinghai-Tibet highway and railway, China. Eng. Geol. 101, 96-109.

Kang, D., Park, S.S., 2002. Emergy evaluation perspectives of a multipurpose dam proposal in Korea. J. Environ. Manage. 66, 293-306.

Kumar, D., Katoch, S.S., 2014. Harnessing 'water tower' into 'power tower': A small hydropower development study from an Indian prefecture in western Himalayas. Renew. Sustain. Energy Rev. 39, 87-101.

Lan, S.F., Qin, P., Lu, H.F., 2002. Emergy analysis of eco-economic system. Chemical Industry 
Press, Beijing (in Chinese).

Lan, Y.C., 2015. The curtain of "Electricity Transfer from Tibet to Outside" has been raised. The Earth (4), 58-60 (in Chinese).

Liu, G.Y., Yang, Z.F., Chen, B., Ulgiati, S., 2011. Monitoring trends of urban development and environmental impact of Beijing, 1999-2006. Sci. Total Environ. 409, 3295-3308.

Liu, H., Masera, D., Esser, L., 2013. World Small Hydropower Development Report 2013. United Nations Industrial Development Organization, International Center on Small Hydro Power. Available at: www.smallhydroworld.org.

Odum, H.T., 1996. Environmental Accounting: Emergy and Environmental Decision Making. Wiley, New York.

Ortega, E., Cavalett, O., Bonifacio, R., Watanabe, M., 2005. Brazilian soybean production: emergy analysis with an expanded scope. Bull. Sci. Technol. Soc. 25, 323-334.

Paish, O., 2002. Small hydro power: technology and current status. Renew. Sustain. Energy Rev. 6, 537-556.

Pang, M.Y., Zhang, L.X., Ulgiati, S., Wang, C.B., 2015. Ecological impacts of small hydropower in China: Insights from an emergy analysis of a case plant. Energy Policy 76, 112-122.

Pulselli, R.M., Simoncini, E., Ridolfi, R., Bastianoni, S., 2008. Specific emergy of cement and concrete: an energy-based appraisal of building materials and their transport. Ecol. Indic. 8, 647-656.

Qiu, J., 2008. China: the third pole. Nature 454, 393-396.

Raugei, S., Bargigli, S., Ulgiati, S., 2005. Emergy “Yield” Ratio—Problems and Misapplication. In: Brown, M.T., Campbell, D., Comar, V., Huang, S.L., Rydberg, T., Tilley, D.R., Ulgiati, S. (Eds.), Emergy Synthesis 3. Theory and Applications of the Emergy Methodology. The 
Center for Environmental Policy, University of Florida, Gainesville, FL, pp. 159-163.

TARG (Tibet Autonomous Region Government), 2011. Tibet autonomous region "12th Five-Year Plan” comprehensive energy development plan. Lhasa (in Chinese).

Ulgiati, S., Bargigli, S., Raugei, M., 2005. Dotting the I's and crossing the T's of emergy synthesis: material flows, information and memory aspects, and performance indicators. In: Brown, M.T., Campbell, D., Comar, V., Huang, S.L., Rydberg, T., Tilley, D.R., Ulgiati, S. (Eds.), Emergy Synthesis 3. Theory and Applications of the Emergy Methodology. The Center for Environmental Policy, University of Florida, Gainesville, FL, pp. 199-213.

Ulgiati, S., Brown, M.T., 1998. Monitoring patterns of sustainability in natural and man-made ecosystems. Ecol. Model. 108, 23-36.

Ulgiati, S., Brown, M.T., 2009. Emergy and ecosystem complexity. Commun. Nonlinear Sci. Numer. Simul. 14, 310-321.

Ulgiati, S., Brown, M.T., 2012. Resource quality, technological efficiency and factors of scale within the emergy framework: A response to Macro Raugei. Ecol. Model. 227, 109-111.

Ulgiati, S., Odum, H.T., Bastianoni, S., 1994. Emergy use, environmental loading and sustainability: an emergy analysis of Italy. Ecol. Model. 73, 215-268.

Wu, X.D., Xia, X.H., Chen, G.Q., Wu, X.F., Chen, B., 2016. Embodied energy analysis for coal-based power generation system-highlighting the role of indirect energy cost. Appl. Energy (In Press).

Wu, X.F., Wu, X.D., Li, J.S., Xia, X.H., Mi, T., Yang, Q., et al., 2014. Ecological accounting for an integrated "pig-biogas-fish" system based on emergetic indicators. Ecol. Indic. 47, 189-197.

Wu, X.F., Yang, Q., Xia, X.H., Wu, T.H., Wu, X.D., Shao, L., et al., 2015. Sustainability of a 
typical biogas system in China: Emergy-based ecological footprint assessment. Ecol. Inform. $26,78-84$.

XHN (Xinhua Net), 2014. Tibet's first large hydropower plant was put into operation to alleviate the electricity shortage in regions with abundant hydropower resources. Available at: http://news.xinhuanet.com/energy/2014-11/24/c_127243915.htm (in Chinese).

Yang, J., Tu, Q., Liu, B.L., 2012. The estimate of sediment loss in the Emergy-based flows of hydropower production system. In: Brown, M.T., Campbell, D., Huang, S.L., Kang, D., Rydberg, T., Tilley, D.R., Ulgiati, S. (Eds.), Emergy Synthesis 7. Theory and Applications of the Emergy Methodology. The Center for Environmental Policy, University of Florida, Gainesville, FL, pp. 235-240.

Yang, Q., Chen, G.Q., Liao, S., Zhao, Y.H., Peng, H.W., Chen, H.P., 2013. Environmental sustainability of wind power: an emergy analysis of a Chinese wind farm. Renew. Sustain. Energy Rev. 25, 229-239.

Yang, Z.F., Jiang, M.M., Chen, B., Zhou, J.B., Chen, G.Q., Li, S.C., 2010. Solar emergy evaluation for Chinese economy. Energy Policy 38, 875-886.

Yao, X.J., Liu, G.X., Zhu, J.L., Yuan, Z.H., Zhang, L., Wang, Y.Q., et al., 2010. Renewable energy and its power generation technology. Science Press, Beijing (in Chinese).

Yi, C.S., Lee, J.H., Shim, M.P., 2010. Site location analysis for small hydropower using geo-spatial information system. Renew. Energy 35, 852-861.

Zhang, L.X., Chen, B., Yang, Z.F., Chen, G.Q., Jiang, M.M., Liu, G.Y., 2009a. Comparison of typical mega cities in China using emergy synthesis. Commun. Nonlinear Sci. Numer. Simul. $14,2827-2836$.

Zhang, L.X., Hu, Q.H., Wang, C.B., 2013. Emergy evaluation of environmental sustainability of 
poultry farming that produces products with organic claims on the outskirts of mega-cities in China. Ecol. Eng. 54, 128-135.

Zhang, L.X., Pang, M.Y., Wang, C.B., 2014. Emergy analysis of a small hydropower plant in southwestern China. Ecol. Indic. 38, 81-88.

Zhang, L.X., Song, B., Chen, B., 2012a. Emergy-based analysis of four farming systems: insight into agriculture diversification in rural China. J. Clean. Prod. 28, 33-44.

Zhang, L.X., Ulgiati, S., Yang, Z.F., Chen, B., 2011. Emergy evaluation and economic analysis of three wetland fish farming systems in Nansi Lake area, China. J. Environ. Manage. 92, 683-694.

Zhang, L.X., Yang, Z.F., Chen, G.Q., 2007a. Emergy analysis of cropping-grazing system in Inner Mongolia Autonomous Region, China. Energy Policy 35, 3843-3855.

Zhang, M.M., Wang, Z.F., Xu, C., Jiang, H., 2012b. Embodied energy and emergy analyses of a concentrating solar power (CSP) system. Energy Policy 42, 232-238.

Zhang, Q.F., Karney, B., MacLean H.L., Feng, J.C., 2007b. Life-cycle inventory of energy use and greenhouse gas emissions for two hydropower projects in China. J. Infrastruct. Syst. 13: 271-279.

Zhang, T.H., 2000. Emphasis of Tibet environmental protection with features of plateau environment. Environ. Protect. (1), 27-29 (in Chinese).

Zhang, X.H., Jiang, W.J., Deng, S.H., Peng, K., 2009b. Emergy evaluation of the sustainability of Chinese steel production during 1998-2004. J. Clean. Prod. 17, 1030-1038.

Zhong, X.H., Liu, S.Z., Wang, X.D., Zhu, W.Z., Li, X.M., Yang, L., 2006. A research on the protection and construction of the state ecological safe shelter zone on the Tibet Plateau. J. Mt. Sci. 24, 129-136 (in Chinese). 
Fig. 1. The main SHP schemes according to the methods of concentrating the water head.

Fig. 2. Location of the study sites and landscape photos of the three SHP plants in eastern Nagqu Prefecture, Tibet.

Fig. 3. Summary diagram of the emergy flows in the three SHP systems: (a) dam-toe SHP system, (b) diversion SHP system, and (c) hybrid SHP system.

Fig. 4. Detailed emergy inputs of the three SHP systems. 


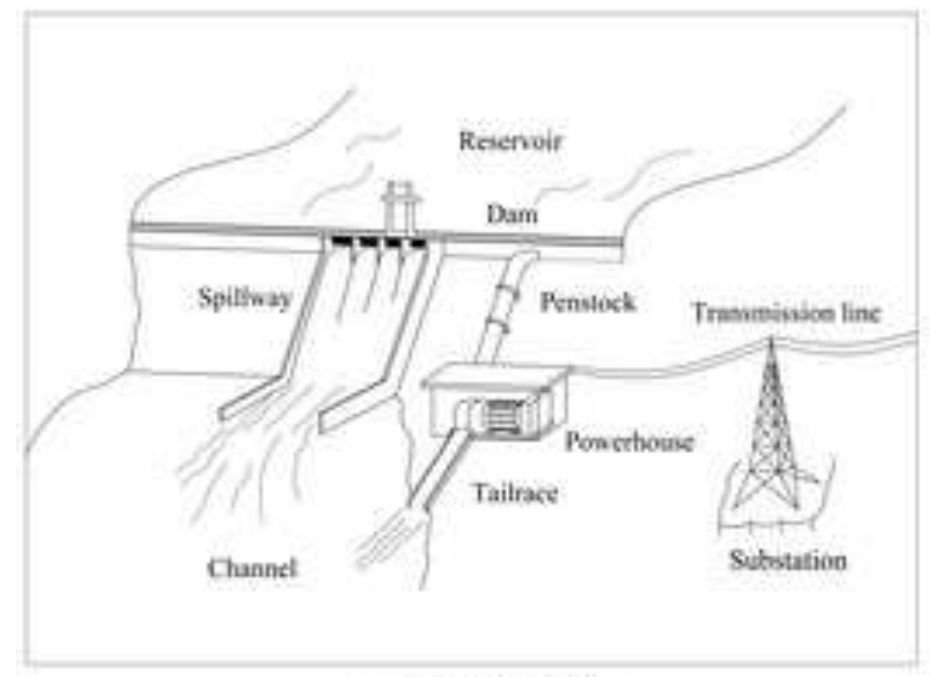

Damineschensesup

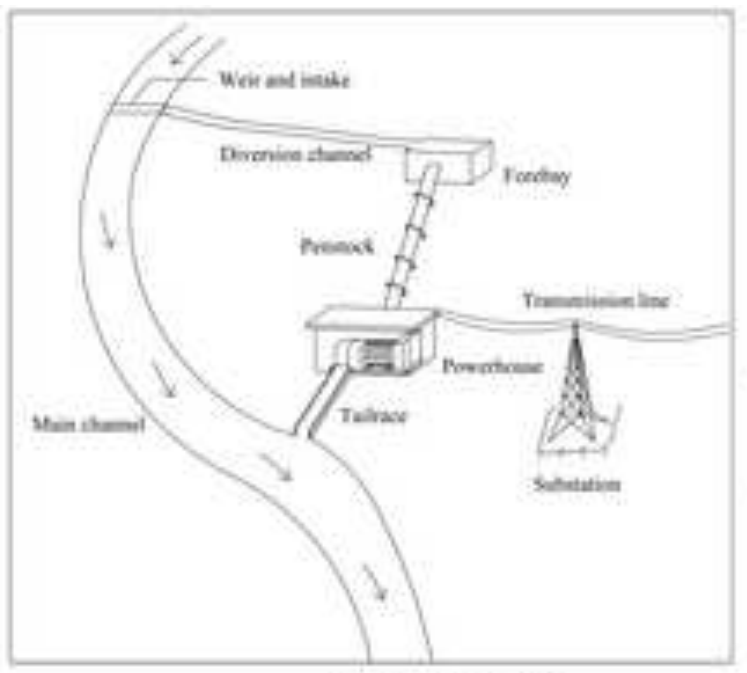

BivessinisthenesนP

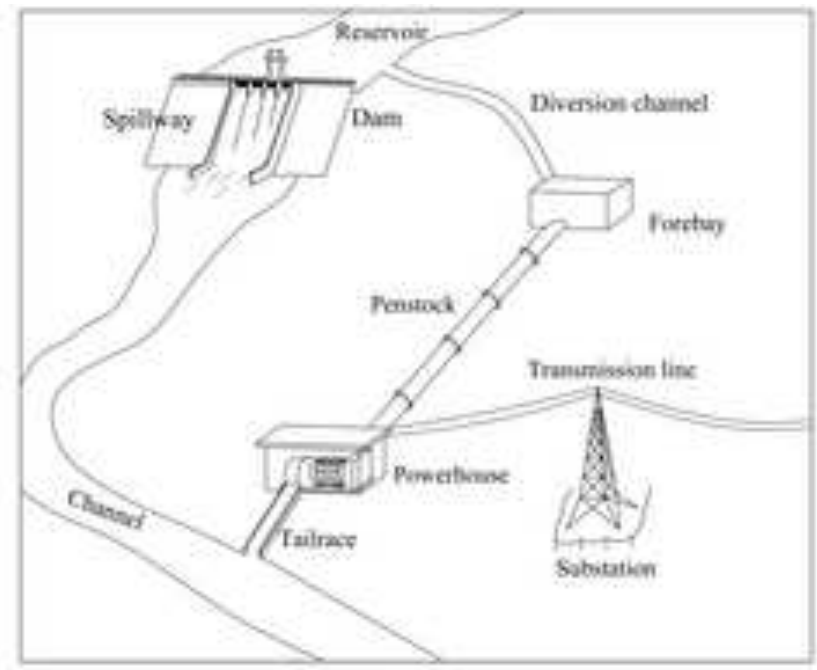

Hytrid-ratane SHP 

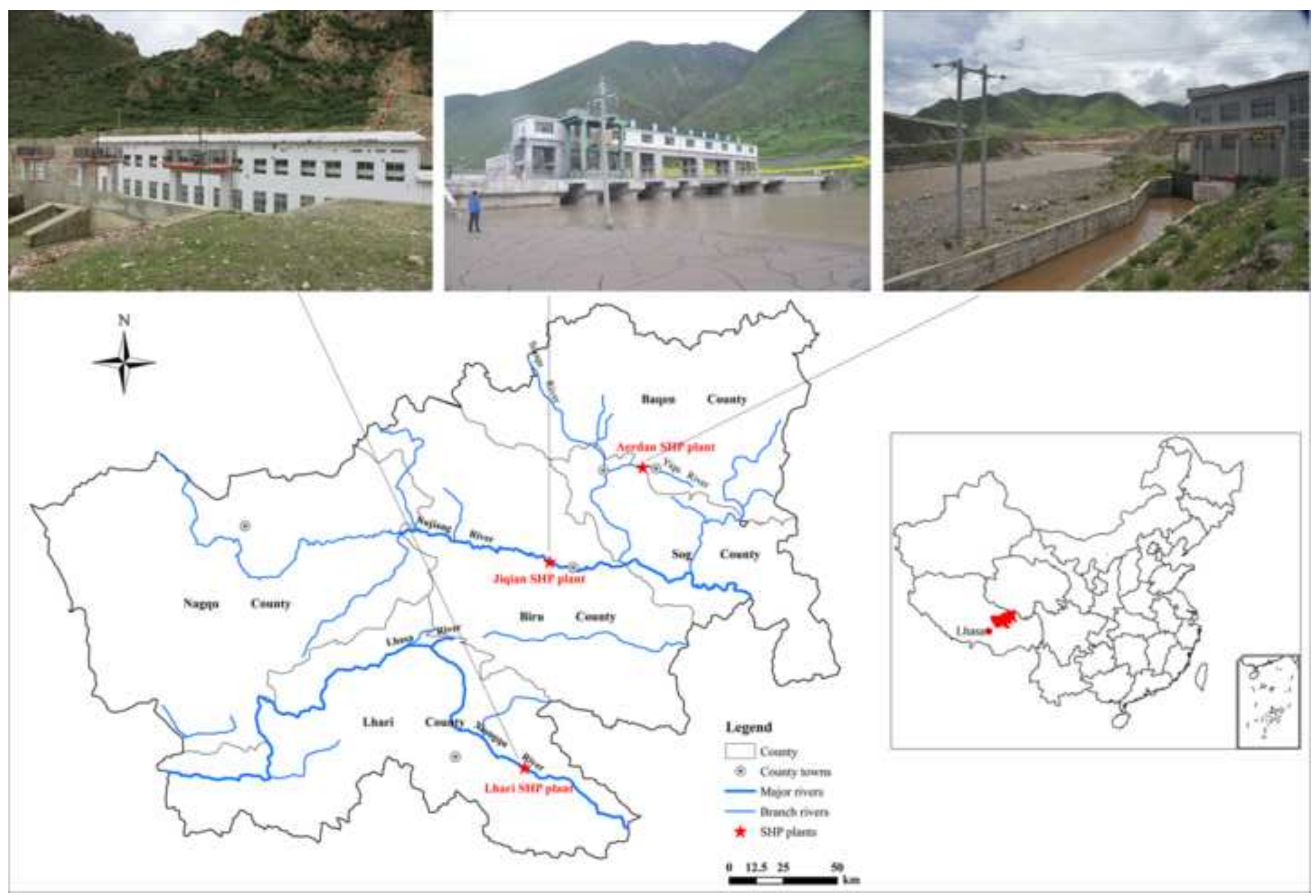

$\square$ County

- Majar minen 
Figure 3

(a)

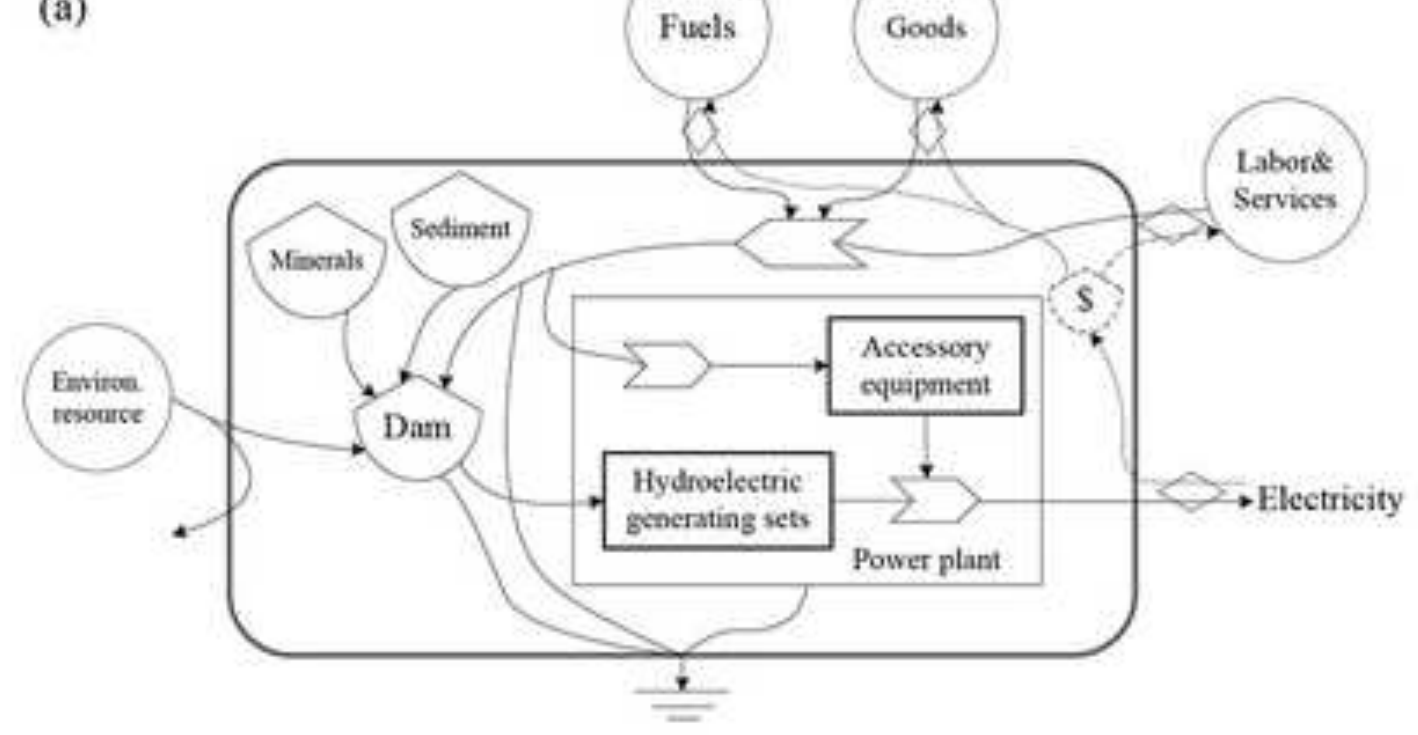

(b)

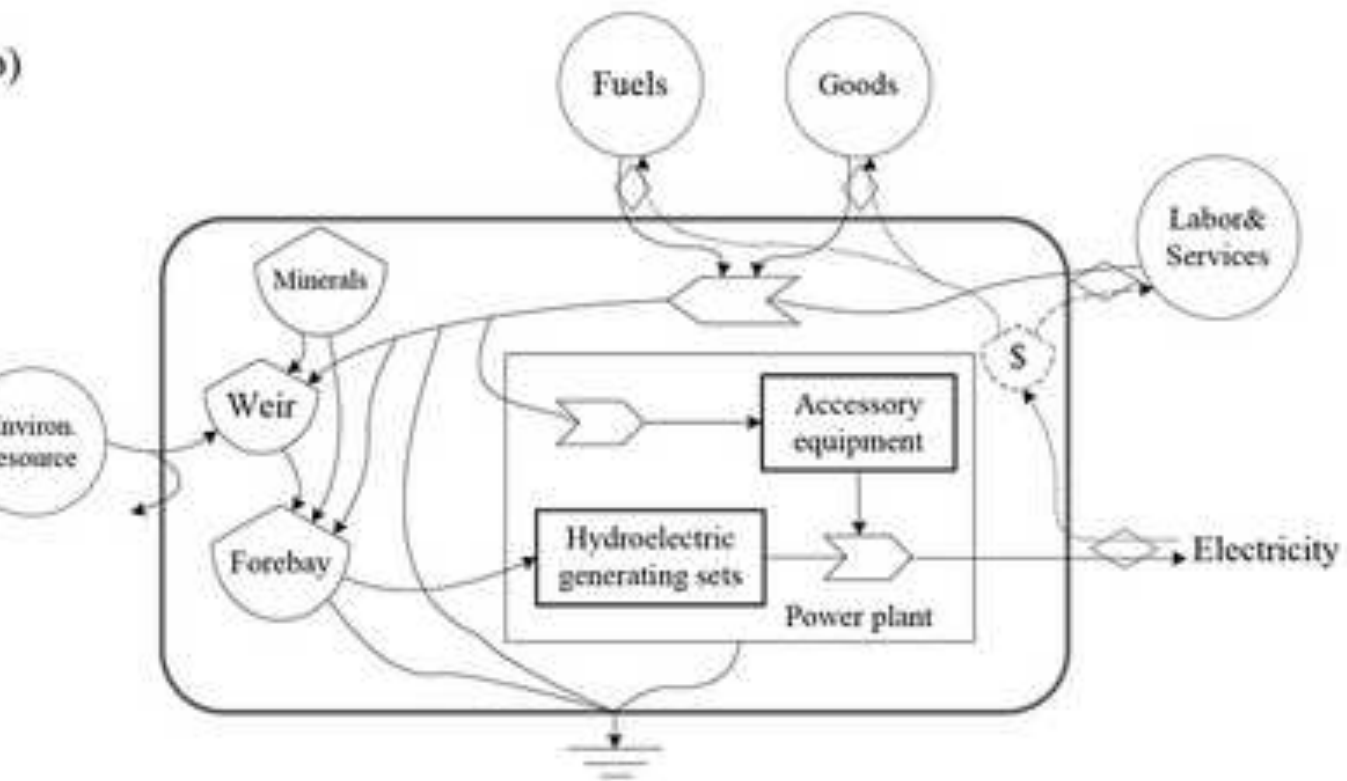

(c)

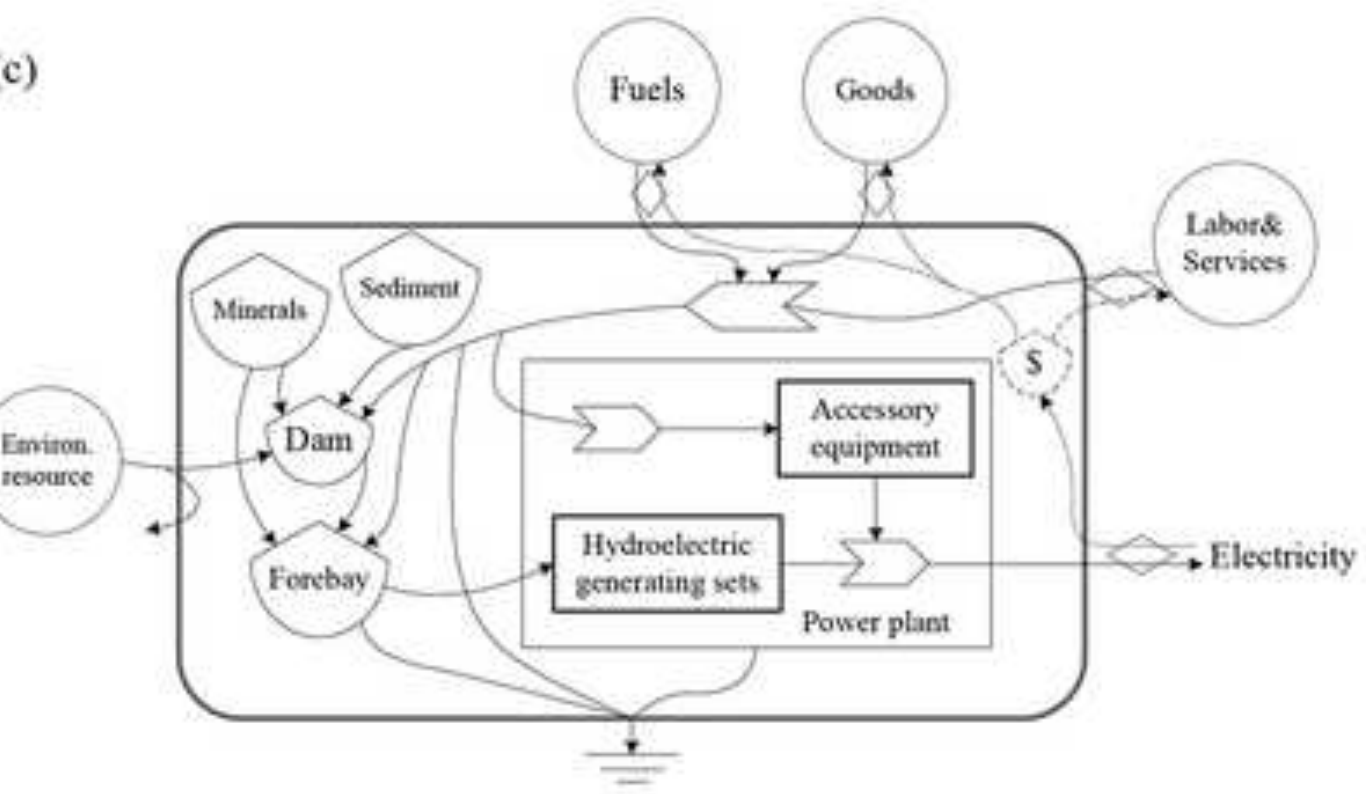




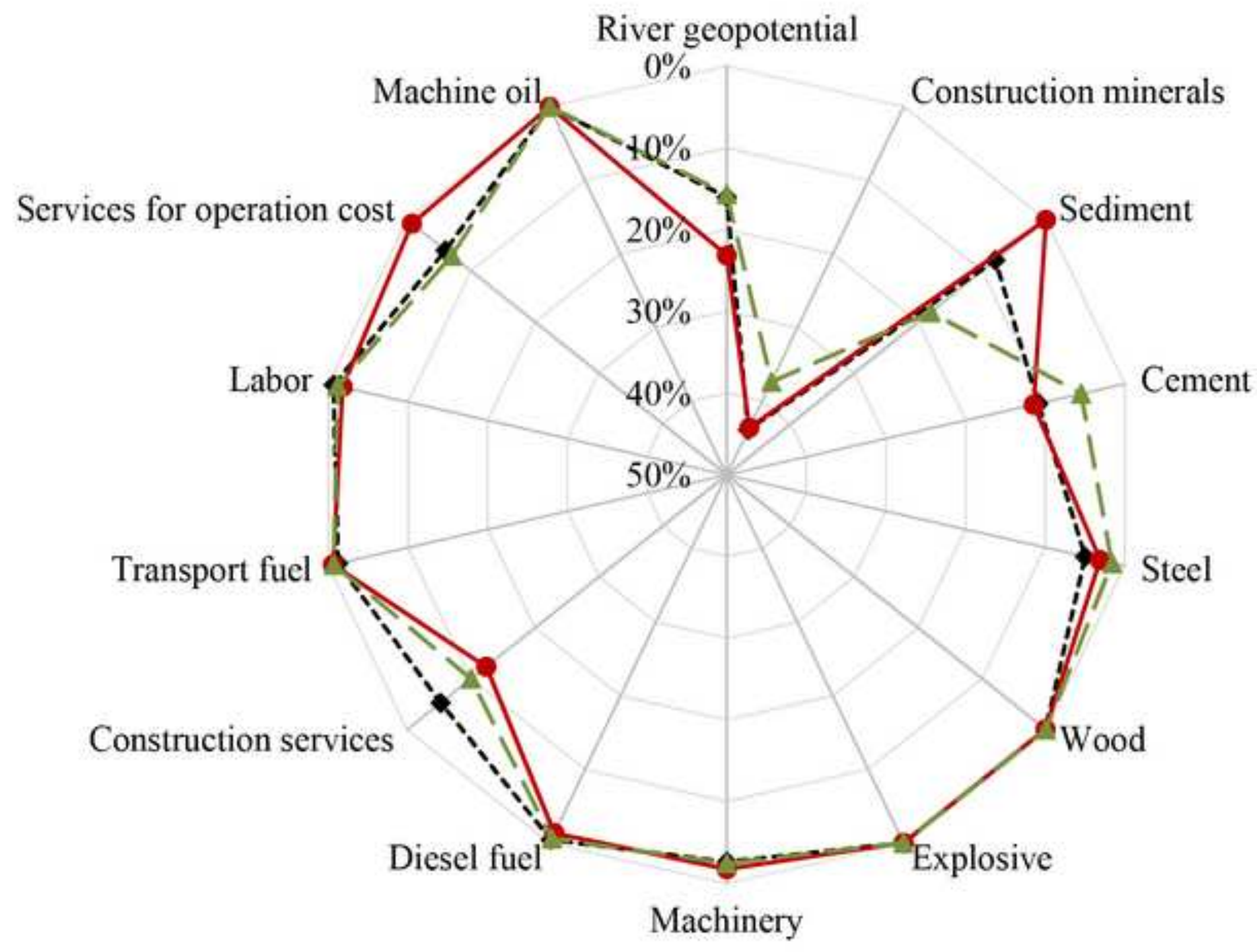

-- - Dam-toe-scheme system $\longrightarrow$ - Diversion-scheme system $\longrightarrow$ Hybrid-scheme system 
Table 1 Description of the three SHP plants in eastern Nagqu Prefecture, Tibet.

\begin{tabular}{llcccccc}
\hline Case & Scheme & $\begin{array}{c}\text { Lifetime } \\
\text { (years) }\end{array}$ & $\begin{array}{c}\text { Installed capacity } \\
(\mathrm{MW})\end{array}$ & $\begin{array}{c}\text { Water Head } \\
(\mathrm{m})\end{array}$ & $\begin{array}{c}\text { Discharge } \\
\left(\mathrm{m}^{3} / \mathrm{s}\right)\end{array}$ & $\begin{array}{c}\text { Annual Operation time } \\
(\mathrm{h})\end{array}$ & $\begin{array}{c}\text { Annual net generation } \\
(\mathrm{GWh})\end{array}$ \\
\hline Jiqian plant & Dam-toe & 20 & 2 & 9 & 29.72 & 6533 & 12.93 \\
Aerdan plant & Diversion & 25 & 0.8 & 10 & 9.76 & 6916 & 4825 \\
Lhari plant & Hybrid & 20 & 1.5 & 33.5 & 5.64 & 4.17 \\
\hline
\end{tabular}


Table 2 Emergy evaluation table for the three SHP schemes in Tibet.

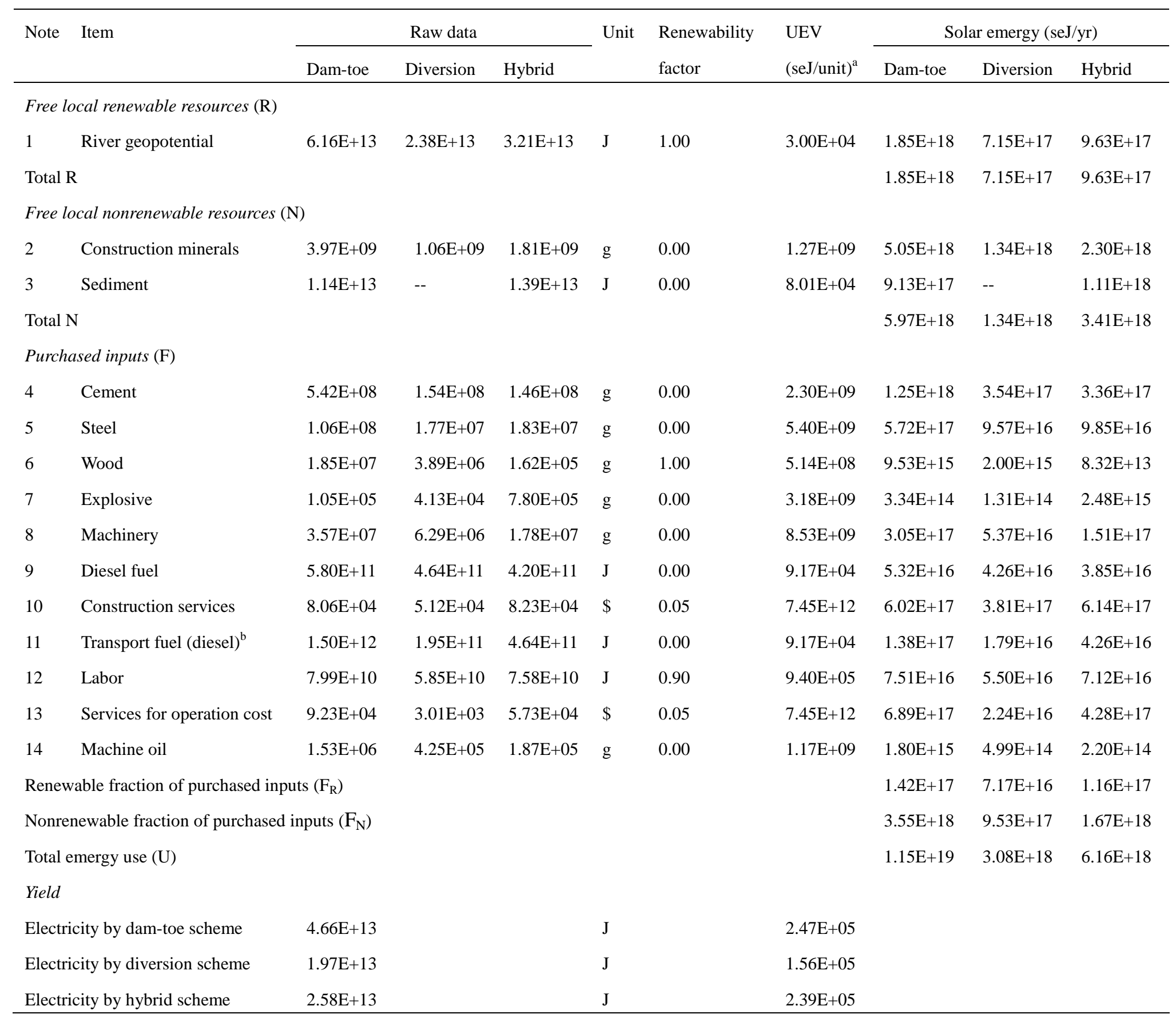

${ }^{a}$ UEV references for respective row numbers: 1. Brown and McClanahan (1996); 2. Chen et al. (2011); 3. Brown and McClanahan (1996); 4. Pulselli et al. (2008); 5. Zhang et al. (2009b); 6. Bastianoni et al. (2001); 7. Brown and Bardi (2001); 8. Brown and McClanahan (1996); 9. Ingwersen (2010); 10. Yang et al. (2010); 11. Ingwersen (2010); 12. Brown and Bardi (2001); 13. Yang et al. (2010); 14. Yang et al. (2013).

${ }^{\mathrm{b}}$ It included the transport of purchased inputs for plant construction from the manufacturer to the plant site. Transport activities associated with the operation and maintenance of the SHP plants were ignored because of lacking data and its expected minor influence on overall evaluation results. 
Table 3 Comparison of emergy indices for the three SHP plants in Tibet and the SHP plant in Guizhou.

\begin{tabular}{|c|c|c|c|c|c|c|c|c|}
\hline Item & Reference & Location & Scheme & $\begin{array}{c}\text { Transformity } \\
\text { seJ/J }\end{array}$ & $\%$ REN & EYR & ELR & ESI \\
\hline Jiqian SHP & Current study & Tibet & Dam-toe & $2.47 \mathrm{E}+05$ & 0.17 & 3.12 & 4.78 & 0.65 \\
\hline Aerdan SHP & Current study & Tibet & Diversion & $1.56 \mathrm{E}+05$ & 0.25 & 3.01 & 2.92 & 1.03 \\
\hline Lhari SHP & Current study & Tibet & Hybrid & $2.39 \mathrm{E}+05$ & 0.18 & 3.45 & 4.71 & 0.73 \\
\hline Hongyan SHP ${ }^{\mathrm{a}}$ & Zhang et al., 2014 & Guizhou Province & Diversion & $7.81 \mathrm{E}+04$ & 0.52 & 4.40 & 0.92 & 4.77 \\
\hline
\end{tabular}

${ }^{a}$ To be more consistent, the emergy baseline of the previous work was scaled up from $15.83 \mathrm{E}+24 \mathrm{seJ} / \mathrm{yr}$ to the most recent $12.0 \mathrm{E}+24 \mathrm{seJ} / \mathrm{yr}$. 